\title{
Closed system RT-qPCR as a potential companion diagnostic test for immunotherapy outcome in metastatic melanoma
}

Swati Gupta', Leena McCann², Yvonne G. Y. Chann ${ }^{2}$, Edwin W. Lai ${ }^{2}$, Wei Wei ${ }^{3}$, Pok Fai Wong ${ }^{1}$, James W. Smithy ${ }^{4}$, Jodi Weidler ${ }^{5}$, Brian Rhees ${ }^{2}$, Michael Bates ${ }^{3}$, Harriet M. Kluger ${ }^{6}$ and David L. Rimm ${ }^{1,6^{*}}$ (D)

\begin{abstract}
Background: In melanoma, there is no companion diagnostic test to predict response to programmed cell death 1 (PD-1) axis immune checkpoint inhibitor (ICl) therapy. In the adjuvant setting, only one in five patients may benefit from $\mathrm{ICl}$, so a biomarker is needed to select those that may or may not benefit. Here, we test a new 4-gene multiplex immunotherapy panel with research use only $(R \cup O)$ prototype mRNA expression profile on the GeneXpert closed system using real-time quantitative reverse transcription polymerase chain reaction (RT-qPCR) for association with clinical benefit after treatment with $\mathrm{ICl}$ therapy in metastatic melanoma patients.

Methods: Pretreatment formalin-fixed paraffin-embedded (FFPE) tissue sections from melanoma patients treated with anti-PD-1 therapy (pembrolizumab, nivolumab, or ipilimumab plus nivolumab) between 2011 and 17 were selected from the Yale Pathology archives. FFPE sections were macrodissected to enrich for tumor for quantitative assessment of CD274 (PD-L1), PDCD1LG2 (PD-L2), CD8A, and IRF1 by RT-qPCR multiplex mRNA panel. Multiplex panel transcript levels were correlated with clinical benefit (complete response [CR], partial response [PR], stable disease [SD]); disease outcomes (progression-free survival [PFS] and overall survival [OS]); and protein levels assessed by quantitative immunofluorescence (QIF).

Results: Transcript levels were significantly higher in responders (CR/PR/SD) than in nonresponders (PD) for CD8A $(p=0.0001)$ and IRF1 $(p=0.0019)$. PFS was strongly associated with high CD274 $(p=0.0046)$, PDCD1LG2 $(p=0.0039), C D 8 A$ $(p=0.0002)$, and IRF1 ( $p=0.0030)$ mRNA expression. Similar associations were observed for OS with high CD274 $(p=0.0004), C D 8 A(p=0.0030)$, and IRF1 ( $p=0.0096)$ mRNA expression. Multivariate analyses revealed significant PFS and OS associations with immunotherapy panel markers independent of baseline variables. Exploratory analyses revealed a novel significant association of high combined CD274 \& PDCD1LG2 (L1/L2) transcript expression with PFS $(p<0.0001)$ and OS $(p=0.0011)$, which remained significant at a multivariate level for both PFS $(H R=0.31)$ and $O S(H R=0.39)$.

Conclusions: Individual immunotherapy panel markers CD274, PDCD1LG2, CD8A, IRF1 and a combined L1/L2 mRNA levels show promising associations with melanoma immunotherapy outcome. The turnaround time of the test ( $2 \mathrm{~h}$ ) and easy standardization of the platform makes this an attractive approach for further study in the search for predictive biomarkers for ICl.
\end{abstract}

\footnotetext{
* Correspondence: david.rimm@yale.edu

'Department of Pathology, Yale University School of Medicine, 310 Cedar

Street, PO Box 208023, New Haven, CT 06510, USA

${ }^{6}$ Department of Internal Medicine (Medical Oncology), Yale University School

of Medicine, New Haven, CT, USA

Full list of author information is available at the end of the article
}

(c) The Author(s). 2019 Open Access This article is distributed under the terms of the Creative Commons Attribution 4.0 International License (http://creativecommons.org/licenses/by/4.0/), which permits unrestricted use, distribution, and reproduction in any medium, provided you give appropriate credit to the original author(s) and the source, provide a link to the Creative Commons license, and indicate if changes were made. The Creative Commons Public Domain Dedication waiver (http://creativecommons.org/publicdomain/zero/1.0/) applies to the data made available in this article, unless otherwise stated. 


\section{Background}

Immune checkpoint blockade (ICI) antibodies targeting cytotoxic T-lymphocyte antigen 4 (CTLA-4) and programmed cell-death protein 1 (PD-1) have shown compelling efficacy in more than 15 cancer types [1]. In advanced melanoma durable response rates (i.e., $>2$ years) for three U.S. Food and Drug Administration (FDA) approved immune checkpoint inhibitor antibodies, ipilimumab (antiCTLA-4), anti-PD-1 (pembrolizumab and nivolumab), and combination of ipilimumab and nivolumab are 11-15, $33-45$ and $60 \%$ respectively $[2,3]$. However, majority of the patients do not respond to monotherapy regime and a subset of patients develop severe adverse events with combination regime [4-7].

In advanced melanoma, PD-L1 IHC 28-8 pharmDx assay is FDA approved as a complementary diagnostic for nivolumab [2, 8]. PD-L1 positive patients are more likely to respond to anti-PD-1 axis ICI than PD-L1 negative patients $[9,10]$. However, the predictive value of PD-L1 expression by IHC in melanoma is controversial, as PD-L1 positive melanoma patients also show better survival in chemotherapy arm [11]. Furthermore, PD-L1 expression in melanoma is low, difficult to measure and quite heterogeneous [12]. Moreover, PD-L1 detection by IHC has major limitations, such as lack of standardization with different antibodies, various cutoffs for scoring and defining positivity $[9,13,14]$. Thus, in metastatic melanoma, there is no companion diagnostic test that can predict response to anti-PD-1 axis immune checkpoint inhibitor therapy.

In the adjuvant setting, only 1 in 5 patients benefit from ICI. There are also relatively severe and prevalent adverse events for a population that may be surgically cured. Thus, there is a more compelling need for a companion diagnostic test in the adjuvant setting than in the metastatic setting. Here, we test a new 4-gene multiplex immunotherapy panel (CD274, PDCD1LG2, CD8A, and IRF1) with research use only (RUO) prototype mRNA expression profile on the GeneXpert closed system using real-time quantitative reverse transcription polymerase chain reaction (RT-qPCR) for association with clinical benefit after treatment with ICI in metastatic melanoma patients toward the goal of a sensitive and specific test for prediction of benefit from ICI.

\section{Methods}

\section{Patient cohort}

Patient cohort is a retrospective collection of 116 melanoma patients treated with anti-PD-1 therapy from 2011 to 17 at Yale. Pretreatment formalin-fixed, paraffin-embedded (FFPE) specimens were reviewed by a board-certified pathologist. The specimens included 78 resections and 38 biopsies. Data were collected from clinical records and the cut-off date was September 2017. A summary of cohort characteristics is detailed in Table 1. All patients provided written informed consent or waiver of consent. The study was approved by the Yale Human Investigation Committee protocol \#9505008219.

\section{Quantitative multiplex RT-PCR}

Quantitative multiplex RT-qPCR was performed using GeneXpert (GX) system. Briefly, $5 \mu \mathrm{M}$ thick FFPE tissue sections were collected and macrodissected to collect tumor. Samples were mixed with $5 \mu$ l Proteinase $K$ and $260 \mu \mathrm{l}$ FFPE lysis reagent. After a 30-min incubation at $80{ }^{\circ} \mathrm{C}, 260 \mu \mathrm{L}$ of $\geq 95 \%$ ethanol was added to the lysed samples and vortexed to mix. This mixture was transferred to the cartridge and was run on the GX system. This assay isolates the total RNA, performs a 1-step RTPCR and provides $\mathrm{Ct}$ values for the endogenous control, POLR2J, and the target genes, CD274, PDCD1LG2, $C D 8 A$ and IRF1. Results were expressed as a delta cycle threshold $(\mathrm{dCt})$ value, defined as the $\mathrm{Ct}$ of the control gene, POLR2J, minus the $\mathrm{Ct}$ of each of the target genes (CD274, PDCD1LG2, CD8A and IRF1). Median values for each marker were used to define high versus low mRNA expression group. For combined CD274 \& PDCD1LG2 (L1/L2) transcript data, we added 10 to individual $\mathrm{dCt}$ values of both the transcripts followed by their addition "[CD274 $(\mathrm{dCt})+10]+[$ PDCD1LG2 $(\mathrm{dCt})$ +10 ]". X-Tile software was used to determine thresholds to define low and high statuses for the $L 1 / L 2$ transcript data [15].

\section{Statistical analysis}

Inter-transcript regression was assessed using nonlinear exponential growth equation $\left(R^{2}\right)$. Response Evaluation Criteria in Solid Tumors (RECIST) 1.1 were used to determine best overall response as complete response $(\mathrm{CR})$, partial response (PR), stable disease (SD), or progressive disease (PD). Disease control rate (DCR; CR/ $\mathrm{PR} / \mathrm{SD}$ ) were correlated with multiplex RT-qPCR immunotherapy panel transcript expression using two-tailed unpaired Student's $t$-tests. Receiver operating characteristic (ROC) curves measured the predictive performance of transcript expression. Kaplan-Meier estimates of progression-free survival (PFS) and overall survival (OS) functions were compared using the log-rank test. Multivariable Cox proportional hazards model included age, sex, mutation status, stage, treatment, and prior ICI as covariates and analyses were carried out using JMP Pro v13.0 (SAS Institute Inc., Cary, NC) statistical analysis software. All data sets were analyzed and plotted using GraphPad Prism v7.0 software for Windows (GraphPad Software, Inc., La Jolla, CA). $P$ values less than 0.05 were considered statistically significant. 
Table 1 Clinicopathological characteristics of the melanoma cohort treated with anti-PD-1 therapy

\begin{tabular}{|c|c|c|c|}
\hline Characteristic & $\begin{array}{l}\text { Anti-PD-1 } \\
\text { patients, } \\
\text { No. (\%) }\end{array}$ & $\begin{array}{l}\text { Objective } \\
\text { response rate (CR/ } \\
\text { PR), No. (\%) }\end{array}$ & $\begin{array}{l}\text { Disease control } \\
\text { rate (CR/PR/SD), } \\
\text { No. }(\%)\end{array}$ \\
\hline Overall & $116(100)$ & $54(47)$ & $80(69)$ \\
\hline \multicolumn{4}{|l|}{ Age (y) } \\
\hline$<65$ & $66(57)$ & $33(61)$ & $50(62)$ \\
\hline$\geq 65$ & $50(43)$ & $21(39)$ & $30(38)$ \\
\hline \multicolumn{4}{|l|}{ Sex } \\
\hline Male & $69(59)$ & $34(63)$ & $47(58)$ \\
\hline Female & $47(41)$ & $20(37)$ & $33(42)$ \\
\hline \multicolumn{4}{|l|}{ Treatment } \\
\hline Pembrolizumab & $41(35)$ & $20(37)$ & $30(38)$ \\
\hline Nivolumab & $18(16)$ & $7(13)$ & $9(11)$ \\
\hline $\begin{array}{l}\text { Ipilimumab } \\
\text { plus nivolumab }\end{array}$ & $57(49)$ & $27(50)$ & $41(51)$ \\
\hline \multicolumn{4}{|c|}{ Prior immune checkpoint blockade } \\
\hline Yes & $36(31)$ & $14(26)$ & $23(29)$ \\
\hline No & $80(69)$ & $40(74)$ & $57(71)$ \\
\hline \multicolumn{4}{|l|}{ Mutation status } \\
\hline BRAF & $39(33)$ & $19(35)$ & $27(34)$ \\
\hline NRAS & $18(16)$ & $8(15)$ & $11(14)$ \\
\hline KIT & $2(2)$ & $1(2)$ & $2(2)$ \\
\hline None detected & $57(49)$ & $26(48)$ & $40(50)$ \\
\hline \multicolumn{4}{|l|}{ Stage at diagnosis } \\
\hline । & $24(21)$ & $14(26)$ & $19(24)$ \\
\hline$\|$ & $23(20)$ & $12(22)$ & $16(20)$ \\
\hline III & $38(32)$ & $16(30)$ & $24(30)$ \\
\hline IV & $20(17)$ & $6(11)$ & $13(16)$ \\
\hline Not available & $11(10)$ & $6(11)$ & $8(10)$ \\
\hline
\end{tabular}

\section{Results}

Inter-transcript regression of immunotherapy markers for melanoma

To assess the mRNA expression of four immunotherapy markers, CD274, PDCD1LG2, CD8A and IRF1, we used a multiplex RT-qPCR immunotherapy panel on the GeneXpert platform in melanoma patients treated with anti-PD-1 therapy. Inter-transcript regression for all four immunotherapy markers showed concordance with $\mathrm{R}^{2}$ ranging from 0.20 to 0.51 (Fig. 1). Specifically, between CD274 and PDCD1LG2 $\left(\mathrm{R}^{2}=0.41\right) ;$ PDCD1LG2 and IRF1 $\left(\mathrm{R}^{2}=0.48\right)$; and CD8A and IRF1 $\left(\mathrm{R}^{2}=0.51\right)$ there was a strong agreement. Regression of transcript $\left(\mathrm{dC}_{\mathrm{t}}\right)$ and protein (QIF scores) measurements using nonlinear exponential growth equation showed high concordance with both CD8 $\left(R^{2}=0.66\right)$ and IRF1 $\left(R^{2}=0.40\right)$, but not PD-L1 $\left(\mathrm{R}^{2}=0.05\right)$ (Additional file 1: Figure S1).
Immunotherapy markers predicts response to anti-PD-1 checkpoint blockade in melanoma

Anti-PD-1 responders (CR/PR/SD, $n=68$ ) and non-responders (PD, $n=29)$ were identified using RECIST category of DCR. Interestingly, high mRNA expression for each of the four immunotherapy markers, CD274 ( $p=0.0187)$, PDCD1LG2 $(p=0.0258), C D 8 A(p<0.0001)$ and IRF1 $(p=0.0019)$ was found to be associated with response to immunotherapy (Fig. 2a). ROC for predictive performance over the range of the transcript expression showed the high discriminatory ability of all four immunotherapy markers. Areas under the ROC curves and their 95\% confidence intervals (CIs) were 0.71 (0.60$0.81)$ for $C D 274,0.68(0.57-0.79)$ for PDCD1LG2, 0.74 (0.63-0.85) for $C D 8 A$, and $0.71(0.60-0.81)$ for IRF1 (Fig. 2b). Similar association using RECIST category of objective response rate were observed for CD8A ( $p=$ $0.0025)$ and IRF1 ( $p=0.0142)$ with response to immunotherapy with and AUC of $0.70(0.59-0.80)$ and 0.65 (0.54-0.76), respectively (Additional File 2: Figure S2).

\section{Survival outcomes and immunotherapy markers in melanoma}

PFS was strongly associated with high CD274 ( $p=$ 0.0046), PDCD1LG2 ( $p=0.0039), C D 8 A \quad(p=0.0002)$, and IRF1 $(p=0.0030)$ transcript expression (Fig. 3a). Similar associations were observed for OS with high CD274 ( $p=0.0004), C D 8 A(p=0.0030)$, and IRF1 ( $p=$ $0.0096)$ transcript expression (Fig. $3 b$ ). Multivariate analyses revealed PFS and OS association with both CD $8 A$ (PFS: HR 0.39, 95\%CI 0.22-0.68, $p=0.0009$ l; OS: HR $0.40,95 \%$ CI $0.18-0.84, p=0.0152$ ) and IRF1 (PFS: HR $0.48,95 \%$ CI $0.26-0.86, p=0.0135$; OS: HR 0.36, 95\% CI $0.16-0.79, p=0.0109$ ) independent of age, sex, stage, mutation, treatment, and prior ICI. In addition, significant association of CD274 (HR 0.30, 95\% CI 0.13-0.66, $p=0.0024$ ) only with OS and PDCD1LG2 (HR 0.49, 95\% CI $0.27-0.89, p=0.0179)$ only with PFS was observed in multivariate analyses (Table 2A).

Since PD-1 antibodies inhibit both the binding of PDL1 and -L2, and since these were the two mRNAs least correlated in expression, we constructed a signature combining both of these variables. The $L 1 / L 2$ combined signature is significantly associated with both PFS $(p<$ $0.0001)$ and $\mathrm{OS}(p=0.0027)$ (Fig. 4a-b). Unlike individual $C D 274$ and PDCD1LG2 expression, the combination of the expression level of the two mRNAs remained significant at a multivariate level for both PFS (HR 0.31, 95\%CI $0.14-0.59, p=0.0003$ ) and OS (HR 0.41, 95\%CI 0.19-0.86, $p=0.0192$ ) (Table 2B).

\section{Discussion}

The goal of this study was to test a new mRNA approach for association with response and outcome in ICI 

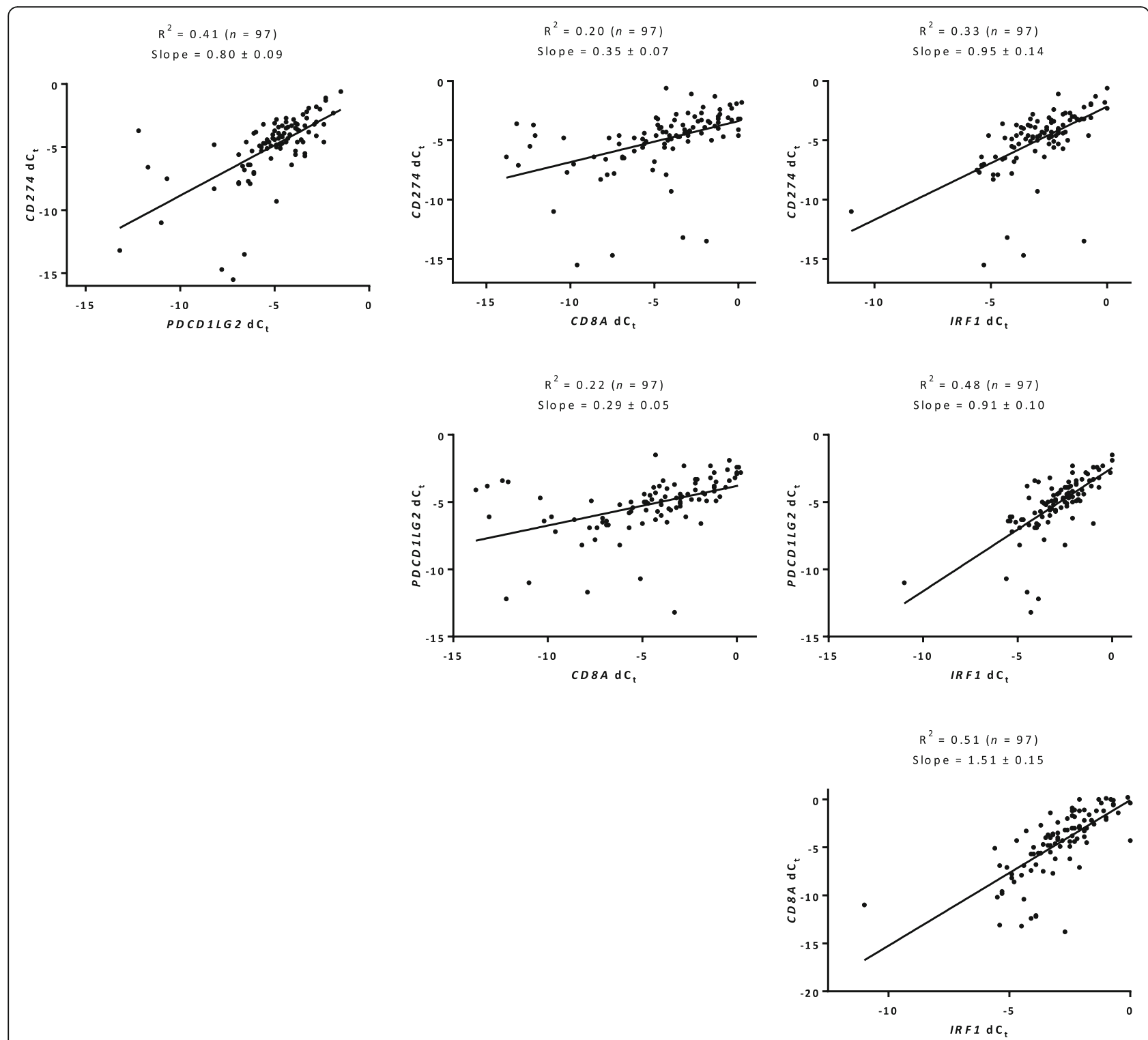

Fig. 1 Inter-transcript regressions in melanoma. Relationship between four transcripts, CD274, PDCD1LG2, CD8A, and IRF1 as determined by multiplex RT-qPCR immunotherapy panel in melanoma patients treated with anti-PD-1 therapy

treated metastatic melanoma. We tested a new 4-gene multiplex immunotherapy panel (CD274, PDCD1LG2, $C D 8 A$, and IRF1) as an mRNA expression profile on the GeneXpert closed system using RT-qPCR. All 4 immunotherapy markers were significantly higher in responders $(\mathrm{CR} / \mathrm{PR} / \mathrm{SD})$ than in non-responders $(\mathrm{PD})$ and a combined CD274 \& PDCD1LG2 model showed associations with survival that was independent of age, sex, mutation status, stage, treatment, and prior ICI.

PD-L1 expression by IHC is the most commonly used predictive marker for response to ICI but it has an AUC of around 0.65 in solid tumors [16-19]. Although IHC is currently the only FDA approved method, the marginal predictive power of PD-L1 detection by IHC has been further limited by lack of standardization between different assays and antibodies, various scoring systems and subjectivity in analysis [9, 13, 14]. These weaknesses have been compounded by the success of the assay in different organ systems with different assays which would suggest that a single lab would need to offer multiple non-standardized tests for the same analyte (PD-L1). Detection of mRNA or mRNA signatures on a standardized, internally controlled, close system platform has the potential to address these weaknesses of IHC.

Efforts to predict outcome with mRNA measurements or mRNA signatures have shown some promise. The first and most significant is probably that by Ayers and colleagues that showed that an 18-gene signature performed 


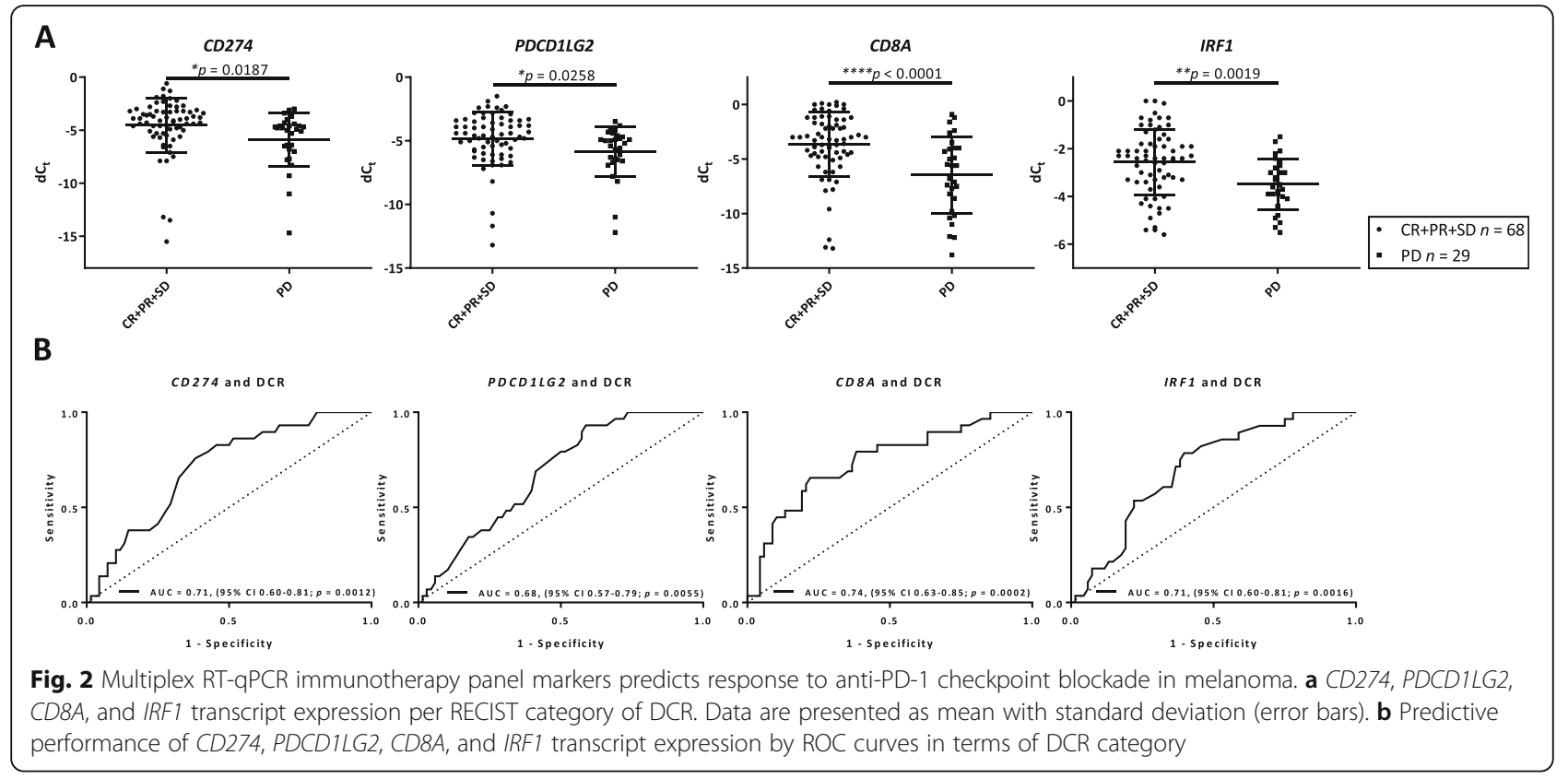

on the Nanostring platform could predict response to pembrolizumab with an AUC around 0.75 [20]. Chen and colleagues also reported that gene expression profiling using a Nanostring panel is predictive of response in patients that received sequential anti-CTLA4 and antiPD-1 therapies [21]. Similarly, meta-analysis by $\mathrm{Lu}$ and colleagues showed that gene expression profiling had predictive value for solid tumors in response to antiPD-1, with an AUC of 0.65 [19]. Of note, a recent study by Pare and colleagues demonstrated that PD-L1 transcript alone, measured via Nanostring platform, had moderate correlation with response to single agent anti-PD-1 therapy across multiple tumor types [22]. Another study by Fehrenbacher and colleagues reported the predictive value of 12-gene signature (T-effector and interferon- $\gamma$ signature) for prolonged OS with Atezolizumab, measured using the Nimblegen platform [23]. In addition, work led by Kowanetz and colleagues showed a 3-gene signature had predictive value for response to Atezolizumab [24]; the signature included CD274 (PD-L1 mRNA), similar to our efforts. Moreover, we observed that PD-L1 expression by closed system immunotherapy assay could predict the response to immunotherapy with an AUC of 0.71 which is marginally better than IHC.. However, this assay solves a

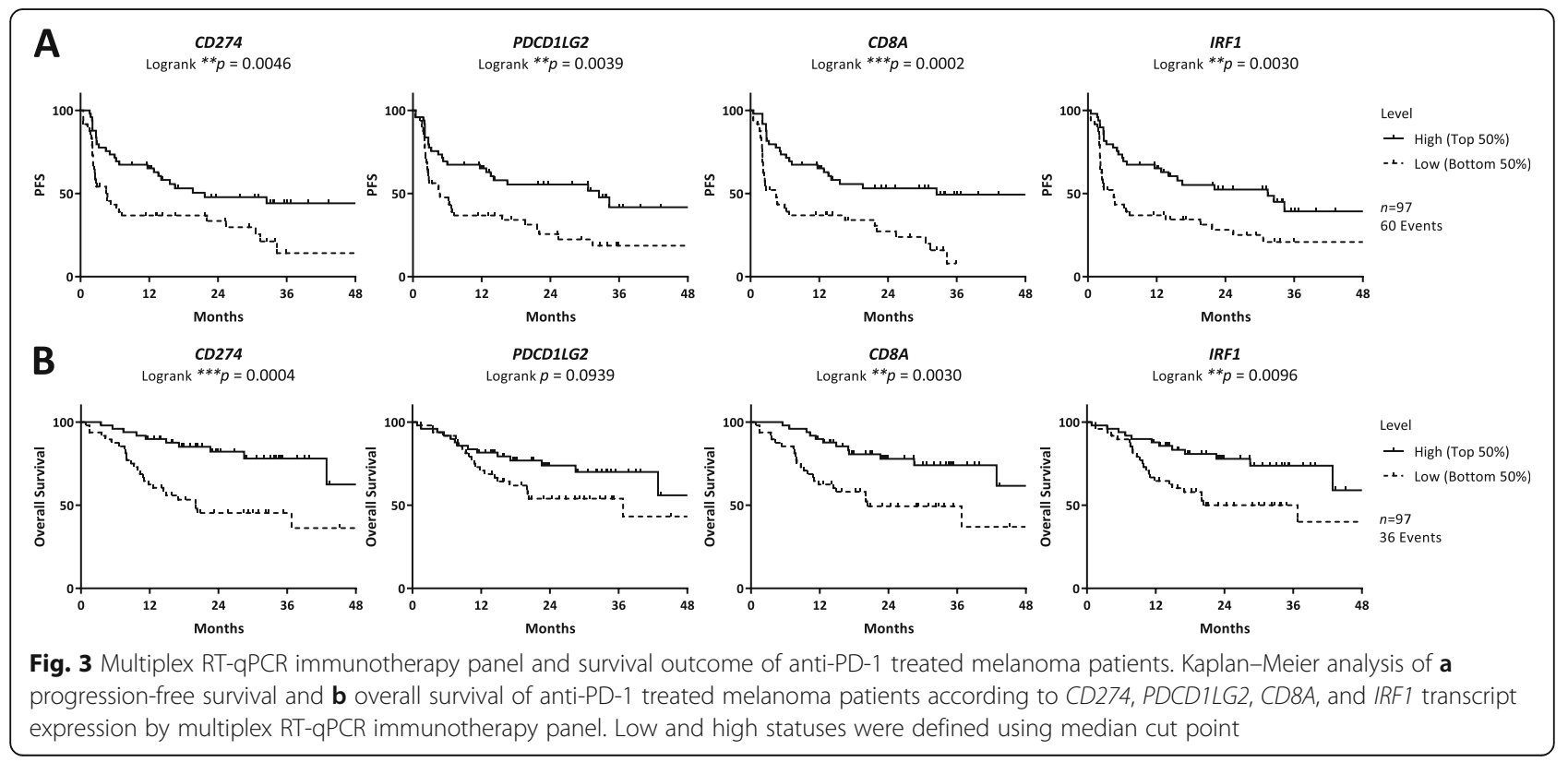


Table 2 Univariate and multivariate Cox regression analyses for progression-free survival and overall survival of melanoma patients and multiplex RT-qPCR immunotherapy panel markers

\begin{tabular}{|c|c|c|c|c|c|c|c|c|}
\hline \multirow[t]{3}{*}{ Variable (HI/LO) } & \multicolumn{4}{|l|}{ PFS } & \multicolumn{4}{|l|}{ OS } \\
\hline & \multicolumn{2}{|c|}{ Univariate analysis } & \multicolumn{2}{|c|}{ Multivariate $^{a}$ analysis } & \multicolumn{2}{|c|}{ Univariate analysis } & \multicolumn{2}{|c|}{ Multivariate* analysis } \\
\hline & $\begin{array}{l}\text { HR } \\
(95 \% \mathrm{Cl})\end{array}$ & $P$ value & $\begin{array}{l}\text { HR } \\
(95 \% \mathrm{Cl})\end{array}$ & $P$ value & $\begin{array}{l}\text { HR } \\
(95 \% \mathrm{Cl})\end{array}$ & $P$ value & $\begin{array}{l}\text { HR } \\
(95 \% \mathrm{Cl})\end{array}$ & $P$ value \\
\hline \multicolumn{9}{|l|}{ A } \\
\hline CD274 & $\begin{array}{l}0.48 \\
(0.29-0.81)\end{array}$ & 0.0053 & $\begin{array}{l}0.57 \\
(0.32-1.03)\end{array}$ & 0.0632 & $\begin{array}{l}0.29 \\
(0.13-0.58)\end{array}$ & 0.0004 & $\begin{array}{l}0.30 \\
(0.13-0.66)\end{array}$ & 0.0024 \\
\hline PDCD1LG2 & $\begin{array}{l}0.47 \\
(0.27-0.79)\end{array}$ & 0.0044 & $\begin{array}{l}0.49 \\
(0.27-0.89)\end{array}$ & 0.0179 & $\begin{array}{l}0.56 \\
(0.28-1.09)\end{array}$ & 0.0936 & $\begin{array}{l}0.52 \\
(0.24-1.11)\end{array}$ & 0.0922 \\
\hline CD8A & $\begin{array}{l}0.36 \\
(0.21-0.61)\end{array}$ & 0.0001 & $\begin{array}{l}0.39 \\
(0.22-0.68)\end{array}$ & 0.0009 & $\begin{array}{l}0.38 \\
(0.18-0.75)\end{array}$ & 0.0051 & $\begin{array}{l}0.40 \\
(0.18-0.84)\end{array}$ & 0.0152 \\
\hline IRF1 & $\begin{array}{l}0.47 \\
(0.28-0.78)\end{array}$ & 0.0035 & $\begin{array}{l}0.48 \\
(0.26-0.86)\end{array}$ & 0.0135 & $\begin{array}{l}0.41 \\
(0.20-0.80)\end{array}$ & 0.0094 & $\begin{array}{l}0.36 \\
(0.16-0.79)\end{array}$ & 0.0109 \\
\hline \multicolumn{9}{|l|}{ B } \\
\hline CD274 \& PDCD1LG2 & $\begin{array}{l}0.30 \\
(0.16-0.57)\end{array}$ & $<0.0001$ & $\begin{array}{l}0.31 \\
(0.14-0.59)\end{array}$ & 0.0003 & $\begin{array}{l}0.38 \\
(0.19-0.73)\end{array}$ & 0.0043 & $\begin{array}{l}0.41 \\
(0.19-0.86)\end{array}$ & 0.0192 \\
\hline
\end{tabular}

${ }^{a}$ Cox proportional hazards model included age, sex, mutation status, stage, treatment, and prior immune checkpoint blockade as covariates $P$ values highlighted in bold are statistically significant

series of major issues associated with PD-L1 IHC including assay variance between vendors, subjective assessment by pathologists, and operator-dependent variation in results. This closed system is objective and operator independent. In summary, while mRNA appears promising, it is too early to determine if this method will gain acceptance in the metastatic setting.

Limited studies have explored the potential role of PD-L2 in predicting response to ICI [10, 25]. Similar to PD-L1, but worse, PD-L2 assessment by IHC has been hampered by lack of validated antibodies and similar IHC issues that have limited PD-L1. Perhaps the most significant effort is that of Yearley and colleagues that showed that high PD-L2 expression was associated with prolonged survival outcome in patients treated with pembrolizumab in Head and Neck Squamous Cell Carcinoma [26]. However, no follow-up data has been published or presented suggesting future use of PD-L2 as a companion diagnostic test.

The secretion of interferon gamma (IFNY) by infiltrating immune cells including, $\mathrm{T}, \mathrm{NK}$, and NK $\mathrm{T}$ cells locally activates JAK/STAT signaling in macrophages and dendritic cells [27]. These cells in turn produce chemokines that recruit additional CD8+ T cells. IFNY also induces synthesis of PD-L1 transcription factor IRF1 and expression of checkpoint inhibitors including PD-L1 and PD-L2 on the surface of tumor, macrophages and dendritic cells $[28,29]$. Of note, all the multiplex immunotherapy panel markers in the study fall under the umbrella of IFNY pathway. Therefore, to assess the relationship between
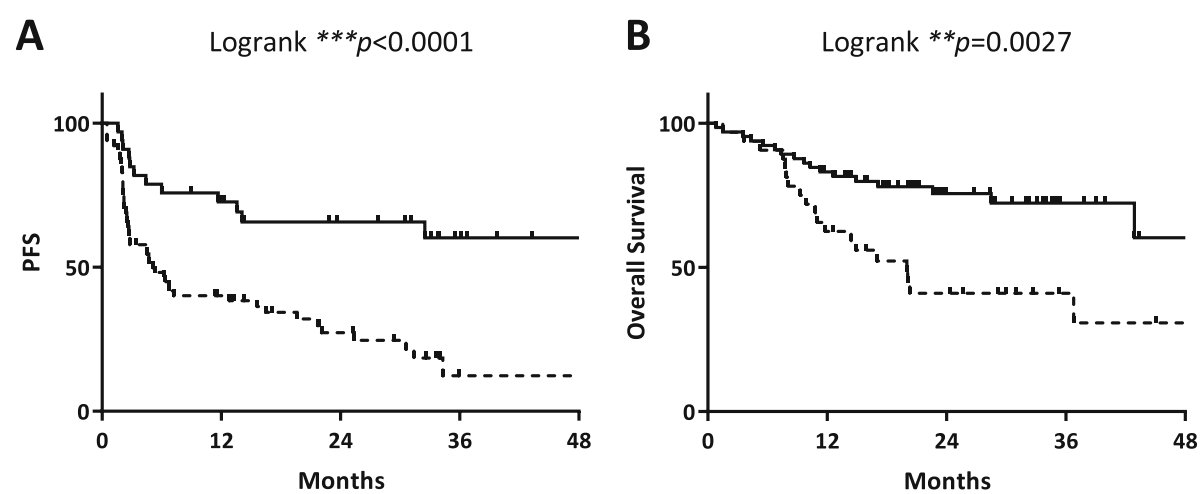

Fig. 4 PD-L1 and PD-L2 combination predicts good survival outcome in anti-PD-1 treated melanoma patients. Kaplan-Meier plots of a progressionfree survival and $\mathbf{b}$ overall survival of anti-PD-1 treated melanoma patients based on combined $L 1 / L 2$ transcript expression by RT-qPCR. Low and high statuses were defined using X-Tile cut point 
these markers, we used Pearson correlation coefficient. As expected, CD274 (PD-L1) correlated with all three genes, including PDCD1LG2 (PD-L2), CD8A and IRF1, which is consistent with the upregulation of IFN $\gamma$ pathway reported in previous literature $[10,26,30,31]$.

The most significant limitation of this work is that our data is a single-institutional retrospective study of immunotherapy treated patients with a modest sample size. It is difficult to access clinical trial material, and hence this sort of pilot level retrospective work is required to show the potential value of new assays. Further investigation to validate the findings presented in this study are underway in collection of a validation cohort from our institution. Another limitation of this work is analyses of melanoma patients treated with either various singleagent immunotherapy or combination immunotherapy as one cohort. Future studies may address this issue by focusing on metastatic melanoma patients that received uniform treatment. Finally, in this retrospective study, we have no control or untreated arm, and thus are unable to calculate an interaction score. As such, we cannot claim predictive value for this assay and simply state that the assay is associated with outcome, without distinguishing prognostic versus predictive value.

\section{Conclusion}

In summary, this study reports the promising association of individual immunotherapy panel markers CD274, PDCD1LG2, CD8A, IRF1 and a combined L1/L2 score (CD274 \& PDCD1LG2) with improved immunotherapy outcome in metastatic melanoma. The closed system mRNA approach introduced in the study has an attractive potential as an easily standardized companion diagnostic with quick turnaround time and potential for use, after further validation, as a companion diagnostic test for ICI therapy.

\section{Supplementary information}

Supplementary information accompanies this paper at https://doi.org/10. 1186/s40425-019-0731-9.

Additional file 1: Figure S1. Transcript versus protein regression. Regression of transcript versus protein for PD-L1, IRF1 and CD8 expression by nonlinear exponential growth equation.

Additional file 2: Figure S2. RECIST category of objective response rate and multiplex RT-qPCR immunotherapy panel markers. (A) CD274, PDCDILG2, CD8A, and IRF1 transcript expression. Data are presented as mean with standard deviation (error bars). (B) Predictive performance of CD274, PDCD1LG2, CD8A, and IRF1 transcript expression by ROC curves.

\section{Abbreviations}

Cls: Confidence intervals; CR: Complete response; CTLA-4: Cytotoxic Tlymphocyte antigen 4; DCR: Disease control rate; dCt: Delta cycle threshold; FDA: U.S. Food and Drug Administration; FFPE: Formalin-fixed paraffinembedded; HR: Hazard Ratio; ICl: Immune checkpoint inhibitor; IFNy: Interferon gamma; IHC: Immunohistochemistry; NSCLS: Non-small cell lung cancer; OS: Overall survival; PD: Progressive disease; PD-1: Programmed cell death 1; PFS: Progression-free survival; PR: Partial response; QIF: Quantitative immunofluorescence; RECIST: Response Evaluation Criteria in Solid Tumors; ROC: Receiver operating characteristic; RTq-PCR: Real-time quantitative reverse transcription polymerase chain reaction; SD: Stable disease

\section{Acknowledgements}

Authors acknowledge the expert assistance of Lori Charette and her team in the Yale Pathology Tissue Services for construction of the tissue sections used in the study.

\section{Authors' contributions}

DLR and SG conceived and designed the study. PFW, JWS, HMK and DLR selected the study cohort, in addition to clinical data collection. SG collected samples, carried out multiplex RT-qPCR immunotherapy panel statistical analysis and drafted the manuscript. LM, and YGYC constructed and performed multiplex RT-qPCR immunotherapy panel assay. WW delivered statistical support. JW, BR and EWL provided technical assistance. MB provided financial support to carry out the study. All authors have revised and approved the final version of the manuscript.

\section{Funding}

This work was supported by a sponsored research agreement with Cepheid and Yale Cancer Center Support Grant P30-CA016359.

\section{Availability of data and materials}

All data generated or analyzed during this study are included in this article and its supplementary information files.

Ethics approval and consent to participate

This study is approved under IRB protocol ID 9505008219.

Consent for publication

Not applicable

\section{Competing interests}

DLR has served as a consultant/advisor to Amgen, Astra Zeneca, Agendia, Biocept, BMS, Cell Signaling Technology, Cepheid, Daiichi Sankyo, GSK, InVicro/Konica Minolta, Merck, Perkin Elmer, PAIGE.Al, and Ultivue. LM, YGYC, EWL, JW, BR and MB declare that they are employees of Cepheid. HMK has received consulting fees from Corvus, Nektar, Biodesix, Genetech, Pfizer, and Celldex, and research support from Apexigen, Merck and BMS. The remaining authors declare no competing interests.

\section{Author details}

'Department of Pathology, Yale University School of Medicine, 310 Cedar Street, PO Box 208023, New Haven, CT 06510, USA. ºncology Research and Development, Cepheid, Sunnyvale, CA, USA. ${ }^{3}$ Department of Biostatistics, Yale School of Public Health, New Haven, CT, USA. 'Department of Medicine, Brigham and Women's Hospital, Boston, MA, USA. ${ }^{5}$ Medical and Scientific Affairs and Strategy, Oncology, Cepheid, Sunnyvale, CA, USA. ${ }^{6}$ Department of Internal Medicine (Medical Oncology), Yale University School of Medicine, New Haven, CT, USA.

Received: 17 April 2019 Accepted: 4 September 2019

Published online: 18 September 2019

References

1. Sharma P, Allison JP. The future of immune checkpoint therapy. Science. 2015:348(6230):56-61.

2. Larkin J, Chiarion-Sileni V, Gonzalez R, Grob JJ, Cowey CL, Lao CD, Schadendorf D, Dummer R, Smylie M, Rutkowski P, Ferrucci PF, Hill A, Wagstaff J, Carlino MS, Haanen JB, Maio M, Marquez-Rodas I, McArthur GA, Ascierto PA, Long GV, Callahan MK, Postow MA, Grossmann K, Sznol M, Dreno B, Bastholt L, Yang A, Rollin LM, Horak C, Hodi FS, Wolchok JD. Combined Nivolumab and Ipilimumab or monotherapy in untreated melanoma. N Engl J Med. 2015;373(1):23-34.

3. Robert C, Schachter J, Long GV, Arance A, Grob JJ, Mortier L, Daud A, Carlino MS, McNeil C, Lotem M, Larkin J, Lorigan P, Neyns B, Blank CU, Hamid O, Mateus C, Shapira-Frommer R, Kosh M, Zhou H, Ibrahim N, 
Ebbinghaus S, Ribas A. Investigators K-. Pembrolizumab versus Ipilimumab in advanced melanoma. N Engl J Med. 2015;372(26):2521-32.

4. Wolchok JD, Chiarion-Sileni V, Gonzalez R, Rutkowski P, Grob JJ, Cowey CL, Lao CD, Wagstaff J, Schadendorf D, Ferrucci PF, Smylie M, Dummer R, Hill A, Hogg D, Haanen J, Carlino MS, Bechter O, Maio M, Marquez-Rodas I, Guidoboni M, McArthur G, Lebbe C, Ascierto PA, Long GV, Cebon J, Sosman J, Postow MA, Callahan MK, Walker D, Rollin L, Bhore R, Hodi FS, Larkin J. Overall survival with combined Nivolumab and Ipilimumab in advanced melanoma. N Engl J Med. 2017;377(14):1345-56.

5. Schadendorf D, Hodi FS, Robert C, Weber JS, Margolin K, Hamid O, Patt D, Chen $\Pi$, Berman DM, Wolchok JD. Pooled analysis of Long-term survival data from phase II and phase III trials of Ipilimumab in Unresectable or metastatic melanoma. J Clin Oncol. 2015;33(17):1889-94.

6. Topalian SL, Sznol M, McDermott DF, Kluger HM, Carvajal RD, Sharfman WH, Brahmer JR, Lawrence DP, Atkins MB, Powderly JD, Leming PD, Lipson EJ, Puzanov I, Smith DC, Taube JM, Wigginton JM, Kollia GD, Gupta A, Pardoll DM, Sosman JA, Hodi FS. Survival, durable tumor remission, and long-term safety in patients with advanced melanoma receiving nivolumab. J Clin Oncol. 2014;32(10):1020-30.

7. Wolchok JD, Weber JS, Maio M, Neyns B, Harmankaya K, Chin K, Cykowski L, de Pril V, Humphrey R, Lebbe C. Four-year survival rates for patients with metastatic melanoma who received ipilimumab in phase II clinical trials. Ann Oncol. 2013;24(8):2174-80.

8. Jorgensen $\mathrm{T}$, Hersom M. Clinical and regulatory aspects of companion diagnostic development in oncology. Clin Pharmacol Ther. 2018;103(6):999-1008.

9. Brahmer JR, Tykodi SS, Chow LQ, Hwu WJ, Topalian SL, Hwu P, Drake CG, Camacho LH, Kauh J, Odunsi K, Pitot HC, Hamid O, Bhatia S, Martins R, Eaton K, Chen S, Salay TM, Alaparthy S, Grosso JF, Korman AJ, Parker SM, Agrawal S, Goldberg SM, Pardoll DM, Gupta A, Wigginton JM. Safety and activity of anti-PD-L1 antibody in patients with advanced cancer. N Engl J Med. 2012;366(26):2455-65.

10. Taube JM, Klein A, Brahmer JR, Xu H, Pan X, Kim JH, Chen L, Pardoll DM, Topalian SL, Anders RA. Association of PD-1, PD-1 ligands, and other features of the tumor immune microenvironment with response to anti-PD1 therapy. Clin Cancer Res. 2014;20(19):5064-74.

11. Robert C, Long GV, Brady B, Dutriaux C, Maio M, Mortier L, Hassel JC, Rutkowski P, McNeil C, Kalinka-Warzocha E, Savage K, Hernberg MM, Lebbe C, Charles J, Mihalcioiu C, Chiarion-Sileni V, Mauch C, Cognetti F, Arance A, Schmidt H, Schadendorf D, Gogas H, Lundgren-Eriksson L, Horak C, Sharkey B, Waxman IM, Atkinson V, Ascierto PA. Nivolumab in previously untreated melanoma without BRAF mutation. N Engl J Med. 2015;372(4):320-30.

12. Madore J, Vilain RE, Menzies AM, Kakavand H, Wilmott JS, Hyman J, Yearley JH, Kefford RF, Thompson JF, Long GV, Hersey P, Scolyer RA. PD-L1 expression in melanoma shows marked heterogeneity within and between patients: implications for anti-PD-1/PD-L1 clinical trials. Pigment Cell Melanoma Res. 2015;28(3):245-53.

13. Gadiot J, Hooijkaas Al, Kaiser AD, van Tinteren $\mathrm{H}$, van Boven $\mathrm{H}$, Blank C. Overall survival and PD-L1 expression in metastasized malignant melanoma. Cancer. 2011:117(10):2192-201.

14. Patel SP, Kurzrock R. PD-L1 expression as a predictive biomarker in Cancer immunotherapy. Mol Cancer Ther. 2015;14(4):847-56.

15. Camp RL, Dolled-Filhart M, Rimm DL. X-tile: a new bio-informatics tool for biomarker assessment and outcome-based cut-point optimization. Clin Cancer Res. 2004;10(21):7252-9

16. Muller T, Braun M, Dietrich D, Aktekin S, Hoft S, Kristiansen G, Goke F, Schrock A, Bragelmann J, Held SAE, Bootz F, Brossart P. PD-L1: a novel prognostic biomarker in head and neck squamous cell carcinoma. Oncotarget. 2017;8(32):52889-900.

17. Garon EB, Rizvi NA, Hui R, Leighl N, Balmanoukian AS, Eder JP, Patnaik A, Aggarwal C, Gubens M, Horn L, Carcereny E, Ahn MJ, Felip E, Lee JS, Hellmann MD, Hamid O, Goldman JW, Soria JC, Dolled-Filhart M, Rutledge RZ, Zhang J, Lunceford JK, Rangwala R, Lubiniecki GM, Roach C, Emancipator K, Gandhi L. Investigators K-. Pembrolizumab for the treatment of non-small-cell lung cancer. N Engl J Med. 2015;372(21):2018-28.

18. Sabatier R, Finetti $P$, Mamessier E, Adelaide J, Chaffanet M, Ali HR, Viens $P$, Caldas C, Birnbaum D, Bertucci F. Prognostic and predictive value of PDL1 expression in breast cancer. Oncotarget. 2015;6(7):5449-64.

19. Lu S, Danilova L, Rimm DL, Hoyt CC, Hellmann M, Taube JM. Comparison of biomarker assay modalities in anti-PD-(L)1 monotherapy: a meta-analysis. SITC. 2018.
20. Ayers M, Lunceford J, Nebozhyn M, Murphy E, Loboda A, Kaufman DR, Albright A, Cheng JD, Kang SP, Shankaran V, Piha-Paul SA, Yearley J, Seiwert TY, Ribas A, McClanahan TK. IFN-gamma-related mRNA profile predicts clinical response to PD-1 blockade. J Clin Invest. 2017;127(8):2930-40.

21. Chen PL, Roh W, Reuben A, Cooper ZA, Spencer CN, Prieto PA, Miller JP, Bassett RL, Gopalakrishnan V, Wani K, De Macedo MP, Austin-Breneman JL, Jiang H, Chang Q, Reddy SM, Chen WS, Tetzlaff MT, Broaddus RJ, Davies MA, Gershenwald JE, Haydu L, Lazar AJ, Patel SP, Hwu P, Hwu WJ, Diab A, Glitza IC, Woodman SE, Vence LM, Wistuba ARN II, Kwong LN, Prieto V, Davis RE, Ma W, Overwijk WW, Sharpe AH, Hu J, Futreal PA, Blando J, Sharma P, Allison JP, Chin L, Wargo JA. Analysis of Immune Signatures in Longitudinal Tumor Samples Yields Insight into Biomarkers of Response and Mechanisms of Resistance to Immune Checkpoint Blockade. Cancer Discov. 2016;6(8):827-37.

22. Pare L, Pascual T, Segui E, Teixido C, Gonzalez-Cao M, Galvan P, Rodriguez A, Gonzalez B, Cuatrecasas M, Pineda E, Torne A, Crespo G, Martin-Algarra S, Perez-Ruiz E, Reig O, Viladot M, Font C, Adamo B, Vidal M, Gaba L, Munoz M, Victoria I, Ruiz G, Vinolas N, Mellado B, Maurel J, Garcia-Corbacho J, Molina-Vila MA, Juan M, Llovet JM, Reguart N, Arance A, Prat A. Association between PD1 mRNA and response to anti-PD1 monotherapy across multiple cancer types. Ann Oncol. 2018;29(10):2121-8.

23. Fehrenbacher L, Spira A, Ballinger M, Kowanetz M, Vansteenkiste J, Mazieres J, Park K, Smith D, Artal-Cortes A, Lewanski C, Braiteh F, Waterkamp D, He P, Zou W, Chen DS, Yi J, Sandler A, Rittmeyer A, Group PS. Atezolizumab versus docetaxel for patients with previously treated non-small-cell lung cancer (POPLAR): a multicentre, open-label, phase 2 randomised controlled trial. Lancet. 2016:387(10030):1837-46.

24. Kowanetz M, Zou W, Gettinger SN, Koeppen H, Kockx M, Schmid P, Kadel EE 3rd, Wistuba I, Chaft J, Rizvi NA, Spigel DR, Spira A, Hirsch FR, Cohen V, Smith D, Boyd Z, Miley N, Flynn S, Leveque V, Shames DS, Ballinger M, Mocci S, Shankar G, Funke R, Hampton G, Sandler A, Amler L, Mellman I, Chen DS, Hegde PS. Differential regulation of PD-L1 expression by immune and tumor cells in NSCLC and the response to treatment with atezolizumab (anti-PD-L1). Proc Natl Acad Sci U S A. 2018;115(43):E10119-26.

25. Schmid P, Hegde PS, Zou W, Kowanetz M, Mariathasan S, Molinero L, Gadgeel SM, Powles T, Heijden MSVD, Fasso M, O'Hear C, Ballinger M, Fine GD, Sandler A, Chen DS, Hodi FS. Association of PD-L2 expression in human tumors with atezolizumab activity. J Clin Oncol. 2016;34(15_suppl):11506.

26. Yearley JH, Gibson C, Yu N, Moon C, Murphy E, Juco J, Lunceford J, Cheng J, Chow LQM, Seiwert TY, Handa M, Tomassini JE, McClanahan T. PD-L2 expression in human tumors: relevance to anti-PD-1 therapy in Cancer. Clin Cancer Res. 2017;23(12):3158-67.

27. Darnell JE Jr, Kerr IM, Stark GR. Jak-STAT pathways and transcriptional activation in response to IFNs and other extracellular signaling proteins. Science. 1994;264(5164):1415-21.

28. Abiko K, Matsumura N, Hamanishi J, Horikawa N, Murakami R, Yamaguchi K, Yoshioka Y, Baba T, Konishi I, Mandai M. IFN-gamma from lymphocytes induces PD-L1 expression and promotes progression of ovarian cancer. Br J Cancer. 2015;112(9):1501-9.

29. Lee SJ, Jang BC, Lee SW, Yang YI, Suh SI, Park YM, Oh S, Shin JG, Yao S, Chen $\mathrm{L}$, Choi IH. Interferon regulatory factor-1 is prerequisite to the constitutive expression and IFN-gamma-induced upregulation of $\mathrm{B} 7-\mathrm{H} 1$ (CD274). FEBS Lett. 2006;580(3):755-62.

30. Smithy JW, Moore LM, Pelekanou V, Rehman J, Gaule P, Wong PF, Neumeister VM, Sznol M, Kluger HM, Rimm DL. Nuclear IRF-1 expression as a mechanism to assess "capability" to express PD-L1 and response to PD-1 therapy in metastatic melanoma. J Immunother Cancer. 2017;5:25.

31. Kluger HM, Zito CR, Barr ML, Baine MK, Chiang VL, Sznol M, Rimm DL, Chen L, Jilaveanu LB. Characterization of PD-L1 expression and associated T-cell infiltrates in metastatic melanoma samples from variable anatomic sites. Clin Cancer Res. 2015;21(13):3052-60.

\section{Publisher's Note}

Springer Nature remains neutral with regard to jurisdictional claims in published maps and institutional affiliations. 